\title{
Coenzyme Q10 ameliorates oxidative stress and prevents mitochondrial alteration in ischemic retinal injury
}

\author{
Dongwook Lee $\cdot$ Keun-Young Kim $\cdot$ Myoung Sup Shim $•$ \\ Sang Yeop Kim • Mark H. Ellisman · Robert N. Weinreb • \\ Won-Kyu Ju
}

Published online: 12 December 2013

(c) The Author(s) 2013. This article is published with open access at Springerlink.com

\begin{abstract}
Coenzyme Q10 (CoQ $\left.{ }_{10}\right)$ acts by scavenging reactive oxygen species for protecting neuronal cells against oxidative stress in neurodegenerative diseases. We tested whether a diet supplemented with $\mathrm{CoQ}_{10}$ ameliorates oxidative stress and mitochondrial alteration, as well as promotes retinal ganglion cell (RGC) survival in ischemic retina induced by intraocular pressure elevation. $\mathrm{A} \mathrm{CoQ}_{10}$ significantly promoted RGC survival at 2 weeks after ischemia. Superoxide dismutase 2 (SOD2) and heme oxygenase-1 (HO-1) expression were significantly increased at $12 \mathrm{~h}$ after ischemic injury. In contrast, the $\mathrm{CoQ}_{10}$ significantly prevented the upregulation of SOD2 and HO-1 protein expression in ischemic retina. In addition, the $\mathrm{CoQ}_{10}$ significantly blocked activation of astroglial and
\end{abstract}

Dongwook Lee and Keun-Young Kim have contributed equally to this work.

Electronic supplementary material The online version of this article (doi:10.1007/s10495-013-0956-x) contains supplementary material, which is available to authorized users.

D. Lee $\cdot$ M. S. Shim $\cdot$ S. Y. Kim · R. N. Weinreb

W.-K. Ju ( $\square)$

Laboratory for Optic Nerve Biology, Department of

Ophthalmology, Hamilton Glaucoma Center, University of

California San Diego, 9415 Campus Point Drive, La Jolla,

CA 92037, USA

e-mail: danielju@glaucoma.ucsd.edu

D. Lee

Research Institute of Clinical Medicine of Chonbuk National University-Biomedical Research Institute, Chonbuk National

University Hospital, Chonju, Chonbuk, Republic of Korea

K.-Y. Kim · M. H. Ellisman

Department of Neuroscience, Center for Research on Biological Systems, National Center for Microscopy and Imaging Research, University of California San Diego, La Jolla, CA, USA microglial cells in ischemic retina. Interestingly, the $\mathrm{CoQ}_{10}$ blocked apoptosis by decreasing caspase-3 protein expression in ischemic retina. Bax and phosphorylated Bad $(\mathrm{pBad})$ protein expression were significantly increased in ischemic retina at $12 \mathrm{~h}$. Interestingly, while $\mathrm{CoQ}_{10}$ significantly decreased Bax protein expression in ischemic retina, $\mathrm{CoQ}_{10}$ showed greater increase of $\mathrm{pBad}$ protein expression. Of interest, ischemic injury significantly increased mitochondrial transcription factor A (Tfam) protein expression in the retina at $12 \mathrm{~h}$, however, $\mathrm{CoQ}_{10}$ significantly preserved Tfam protein expression in ischemic retina. Interestingly, there were no differences in mitochondrial DNA content among control- or $\mathrm{CoQ}_{10^{-}}$ treated groups. Our findings demonstrate that $\mathrm{CoQ}_{10}$ protects RGCs against oxidative stress by modulating the Bax/ Bad-mediated mitochondrial apoptotic pathway as well as prevents mitochondrial alteration by preserving Tfam protein expression in ischemic retina. Our results suggest that $\mathrm{CoQ}_{10}$ may provide neuroprotection against oxidative stress-mediated mitochondrial alterations in ischemic retinal injury.

Keywords Coenzyme Q10 - Retinal ischemia - Retinal ganglion cell $\cdot$ Oxidative stress $\cdot$ Mitochondrial transcription factor A - Mitochondrial DNA

\section{Introduction}

Elevated intraocular pressure (IOP) is an important risk factor for retinal ganglion cell (RGC) death and optic nerve degeneration in retinal ischemia and glaucoma [1]. Growing evidence indicates that ischemic injury by acute IOP elevation alters mitochondrial dynamics-related proteins and induces mitochondrial dysfunction-mediated apoptotic 
cell death in the retina of rodent models [2, 3]. Importantly, our previous studies demonstrated that IOP elevation triggered release of mitochondrial fusion protein optic atrophy 1 and increase of mitochondrial fission GTPase dynamin related protein-1, as well as induced apoptotic cell death by modulating Bax/phosphorylated $\mathrm{Bad}(\mathrm{pBad})$ protein expression in ischemic retina [2,3]. Collectively, these findings suggest that ischemic injury induced by acute IOP elevation is associated with mitochondrial dysfunctionmediated apoptotic pathway in the retina.

Oxidative stress has been implicated as an important pathophysiological mechanism for mitochondrial dysfunction-mediated retinal neurodegeneration including ischemic injury [4-7]. Superoxide dismutases (SODs), cytosolic SOD1 and mitochondrial SOD2, are expressed in the ganglion cell layer (GCL) and inner plexiform layer in rodent retina [8]. A recent study suggests that SOD2 has a protective role against oxidative stress-mediated neuronal cell death [9]. Of interest, we found that acute IOP elevation significantly increased SOD2 protein expression in the early neurodegeneration of ischemic rat retina [5]. In addition, increasing evidence indicates that oxidative stress is associated with mitochondrial DNA (mtDNA) alterationrelated mitochondrial dysfunction in retinal neurodegeneration $[5,7,10,11]$. However, it remains unknown whether oxidative stress induced by acute IOP elevation causes mtDNA alteration in ischemic retinal injury.

Mitochondrial transcription factor A (Tfam, also as known as mtTFA), a nucleus encoded DNA-binding protein in mitochondria, has an important role in mitochondrial gene expression and mtDNA maintenance, and therefore is essential for oxidative phosphorylation (OXPHOS)-mediated adenosine triphosphate (ATP) synthesis [12-15]. Mice lacking Tfam have impaired mtDNA transcription and loss of mtDNA leads to bioenergetics dysfunction and embryonic lethality [12]. In contrast, overexpression of Tfam mediates delayed neuronal death following transient forebrain ischemia in mice [16-18] as well as neonatal hypoxic-ischemic brain injury rapidly increased Tfam and OXPHOS complex IV protein expression in a rat model [19]. This suggests that these responses may support endogenous repair mechanisms for mtDNA damage following hypoxic-ischemic brain injury [19]. Of note, acute IOP elevation significantly increased Tfam and OXPHOS complex protein expression in the early neurodegeneration of ischemic rat retina [5], collectively suggesting that these responses may reflect endogenous repair mechanisms for elevated IOP-induced mitochondrial alteration in ischemic injury.

Coenzyme Q10 $\left(\mathrm{CoQ}_{10}\right)$, an essential cofactor of the electron transport chain, acts by maintaining the mitochondrial membrane potential, supporting ATP synthesis and inhibiting reactive oxygen species (ROS) generation for protecting neuronal cells against oxidative stress in neurodegenerative diseases [20-22]. Previous studies have demonstrated that $\mathrm{CoQ}_{10}$ protected retinal neurons against hydrogen peroxide-induced oxidative stress in vitro [23] as well as prevented retinal damage caused by acute high IOP-induced transient ischemic injury [24, 25].

In the current study, we tested whether a diet supplemented with $\mathrm{CoQ}_{10}$ ameliorates oxidative stress-mediated apoptotic cell death in RGC degeneration by preventing mitochondrial alteration in ischemic mouse retina.

\section{Materials and methods}

Animals

Female, 4-month-old C57BL/6 mice (20-25 g in weight; The Jackson Laboratories, Bar Harbor, ME, USA) were housed in covered cages, fed with a standard rodent diet ad libitum, and kept on a $12 \mathrm{~h}$ light/12 h dark cycle. All procedures concerning animals were performed in accordance with the ARVO statement for the Use of Animals in Ophthalmic and Vision Research and under protocols approved by institutional IACUC committees at the University of California San Diego.

\section{Induction of transient retinal ischemia}

The mice were anesthetized with a mixture of ketamine $(100 \mathrm{mg} / \mathrm{kg}$, Ketaset; Fort Dodge Animal Health, Fort Dodge, IA, USA) and xylazine $(9 \mathrm{mg} / \mathrm{kg}$, TranquiVed; Vedeco, Inc., St. Joseph, MO, USA) by intraperitoneal (IP) injection. Eyes were also treated with $1 \%$ proparacaine drops. A 30-gauge needle was inserted into the anterior chamber of right eye that was connected by flexible tubing to a saline reservoir. By raising the reservoir, IOP was elevated to $70-80 \mathrm{mmHg}$ for $50 \mathrm{~min}$. Sham treatment was performed in the contralateral eyes by the insertion of a needle in the anterior chamber without saline injection. Retinal ischemia was confirmed by observing whitening of the iris and loss of the retina red reflex. IOP was measured with a tonometer (TonoLab; Tiolatoy, Helsinki, Finland) during ischemia. Non-ischemic contralateral control retinas were used as control.

Pharmacological treatment

$\mathrm{CoQ}_{10}$ was purchased from Kaneka Nutrients (Pasadena, TX, USA) or Sigma (St. Louis, MO, USA). AIN-93G purified control or a diet supplemented with $\mathrm{CoQ}_{10}$ were formulated by Harlan Laboratories (Madison, WI, USA). Four groups of mice were studied: a group of non-ischemic C57BL/6 mice treated with control diet $(n=20$ mice $)$, a 
group of ischemic C57BL/6 mice treated with control diet ( $n=30$ mice), a group of non-ischemic C57BL/6 mice treated with $1 \% \mathrm{CoQ}_{10} \operatorname{diet}[(\mathrm{v} / \mathrm{v})$, which equals a daily dose of $1,600-2,000 \mathrm{mg} / \mathrm{kg}$ body weight in $25-30 \mathrm{~g}$ mice, $n=20$ mice] [26] and a group of ischemic C57BL/6 mice treated with $1 \% \mathrm{CoQ}_{10} \operatorname{diet}(n=30$ mice $)$.

\section{Tissue preparation}

Six to $24 \mathrm{~h}$ after acute IOP elevation, light adapted mice were anesthetized with IP injection of mixture of ketamine/ xylazine, as described, and then mice were perfused transcardially with $0.9 \%$ saline followed by $4 \%$ paraformaldehyde in $1 \mathrm{X}$ phosphate buffer saline (PBS, pH 7.4). Both eyes enucleated and fixed in $4 \%$ paraformaldehyde in PBS for $4 \mathrm{~h}$ at $4{ }^{\circ} \mathrm{C}$. After several washes in PBS, the retinas were dissected and then dehydrated through graded ethanol solutions and embedded in polyester wax, as described previously [27].

Whole-mount immunohistochemical analysis

Retinas from enucleated eyes were dissected as flattened whole-mounts at $12 \mathrm{~h}$ or 2 weeks after ischemia-reperfusion. Retinas were immersed in PBS containing $30 \%$ sucrose for $24 \mathrm{~h}$ at $4{ }^{\circ} \mathrm{C}$. The retinas were blocked in PBS containing $3 \%$ donkey serum, $1 \%$ bovine serum albumin, $1 \%$ fish gel and $0.1 \%$ Triton X-100 for $1 \mathrm{~h}$, and incubated with goat polyclonal anti-Brn3a antibody (1:500; Santa Cruz Biotechnology, Santa Cruz, CA, USA), a specific maker for RGCs [28, 29], and guinea pig polyclonal antiGFAP antibody (1:500; Advanced ImmunoChemical, Long Beach, CA, USA) for 3 days at $4{ }^{\circ} \mathrm{C}$. After several wash steps, the retinas were incubated with the secondary antibodies, Alexa Fluor-568 donkey anti-goat IgG antibody or Cy5-conjugated anti-guinea pig IgG antibody (Invitrogen, Carlsbad, CA, USA) for $24 \mathrm{~h}$, and subsequently washed with PBS. The retinas were counterstained with the nucleic acid stain Hoechst $33342(1 \mu \mathrm{g} / \mathrm{mL}$; Invitrogen) in PBS. Images were captured under fluorescence microscopy (Eclipse microscope, model E800; Nikon instruments Inc., Meliville, NY, USA) equipped with a digital camera (SPOT; Diagnostic Instrument, Sterling Heights, MI, USA). Images were acquired with commercial software (Simple PCI version 6.0 software; Compix Inc., Cranberry Township, PA, USA).

\section{Quantitative analysis for RGC counting}

To count RGCs labeled with Brn3a, each retinal quadrant was divided into three zones by central, middle, and peripheral retina [one sixth $(\sim 400 \mu \mathrm{m})$, three sixths $(\sim 1,200 \mu \mathrm{m})$, and five sixths $(\sim 2,000 \mu \mathrm{m})$ of the retinal radius from the optic nerve head]. Images were taken at $20 \times$, covering an area of $0.344 \mathrm{~mm}^{2}$, and then the number of RGCs were normalized per $\mathrm{mm}^{2}$. RGC densities were measured in 24 distinct areas (two areas at central, middle, and peripheral per retinal quadrant) per condition by two investigators in a masked fashion, and the scores were averaged ( $n=7$ retinas/group). To further examine RGC survival between control and $\mathrm{CoQ}_{10}$ diet-treated nonischemic retinas, RGC densities were automatically measured using ImageJ cell counting analysis (http://rsb.info. nih.gov/ij/, National Institute of Health, Bethesda, MD, USA).

Immunohistochemical analysis

Immunohistochemical staining of retinal cross sections at $12 \mathrm{~h}$ after transient ischemia was performed as previously described [27]. Five sections per wax block from each group were used for immunohistochemical analysis. Primary antibodies were goat polyclonal anti-Brn3a antibody (1:500; Santa Cruz Biotechnology, Santa Cruz, CA, USA), a specific maker for RGCs [30], monoclonal mouse antiGFAP antibody (1:500; Sigma, St. Louis, MO, USA) and rabbit polyclonal anti-Iba1 antibody (1:500; Wako Chemicals USA, Inc., Richmond, VA, USA). To prevent nonspecific background, tissues were incubated in $1 \%$ bovine serum albumin/PBS for $1 \mathrm{~h}$ at room temperature before incubation with the primary antibodies for $16 \mathrm{~h}$ at $4{ }^{\circ} \mathrm{C}$. After several wash steps, the tissues were incubated with the secondary antibodies, Alexa Fluor 568 dye-conjugated donkey anti-goat IgG antibody (Invitrogen, Carlsbad, CA, USA), Cy5 dye-conjugated goat anti-mouse IgG antibody (Invitrogen) or Alexa Fluor 488 dye-conjugated anti-rabbit IgG antibody (1:100; Invitrogen) for $4 \mathrm{~h}$ at $4{ }^{\circ} \mathrm{C}$ and subsequently washed with $\mathrm{PBS}$. The sections were counterstained with the nucleic acid stain Hoechst 33342 (Invitrogen) in PBS. Images were acquired with confocal microscopy (Olympus FluoView1000; Olympus, Tokyo, Japan).

\section{Western blot analysis}

Following 6, 12 or $24 \mathrm{~h}$ after transient ischemia, the collected retinas were homogenized in a glass-Teflon Potter homogenizer in RIPA lysis buffer $(150 \mathrm{mM} \mathrm{NaCl}, 1 \mathrm{mM}$ EDTA, $1 \%$ NP-40, $0.1 \%$ SDS, 1 mM DTT, $0.5 \%$ sodium deoxycholate and $50 \mathrm{mM}$ Tris- $\mathrm{Cl}, \mathrm{pH}$ 7.6) containing complete protease inhibitors (Roche Biochemicals, Indianapolis, IN, USA). Each sample $(10 \mu \mathrm{g} ; n=3$ retinas/ group) was separated by PAGE and electrotransferred to polyvinylidenedifluoride membrane. The membrane was blocked with $5 \%$ nonfat dry milk and $0.1 \%$ Tween-20 in PBS for $1 \mathrm{~h}$, incubated with rabbit polyclonal anti-SOD2 
antibody (1:5000; Santa Cruz Biotechnology), rabbit polyclonal anti-HO-1 antibody (1:1000; Millipore), monoclonal mouse anti-GFAP (1:3000; Sigma), rabbit polyclonal anti-Iba-1 antibody (1:2000; Wako Chemical USA), mouse monoclonal anti-caspase antibody (1:3000; Cell Signaling, Danvers, MA, USA), rabbit polyclonal antiBax antibody (1:500; Santa Cruz Biotechnology), mouse monoclonal anti-phosphorylated Bad (pBad, 1:2000; Cell Signaling), goat polyclonal anti-Tfam antibody (1:1000; Santa Cruz Biotechnology), rabbit polyclonal anti-Porin (1:1000; Calbiochem, La Jolla, CA, USA) and mouse monoclonal anti-actin antibody (1:10,000, Millipore, Billerics, MA, USA) for overnight at $4{ }^{\circ} \mathrm{C}$. After several washes in Tween/PBS, the membranes were incubated with peroxidase-conjugated donkey anti-goat IgG (1:5000: BioRad, Hercules, CA, USA), goat anti-rabbit IgG (1:5000; Bio-Rad) or goat anti-mouse IgG (1:5000; Bio-Rad), and developed using chemiluminescence detection (ECL Plus; GE Healthcare Bio-Science, Piscataway, NJ, USA). The scanned film Images were analysed by ImageJ (National Institute of Health) and band densities were normalized to the band densities for actin or porin.

\section{TUNEL staining}

The retinal cross sections at $12 \mathrm{~h}$ after transient ischemia were incubated with proteinase $\mathrm{K}(10 \mu \mathrm{g} / \mathrm{mL}, 10 \mathrm{mM}$ Tris, $\mathrm{pH}$ 7.4-8.0) for $10 \mathrm{~min}$ at $37^{\circ} \mathrm{C}$. After rinsing in PBS, the sections were incubated with terminal deoxynucleotidyl transferase plus nucleotide mixture in reaction buffer for $60 \mathrm{~min}$ at $37{ }^{\circ} \mathrm{C}$ (In situ Cell Death Detection kit, Roche Applied Science, Indianapolis, IN, USA) as previously described [3]. To count TUNEL-positive cells, the areas were divided into three layers by GCL, inner nuclear layer (INL) and outer nuclear layer (ONL). TUNEL-positive cells were counted in eight microscopic fields of $0.2 \mathrm{~mm}$ from retinal sections per condition ( $n=5$ retinas/group) by two investigators in a masked fashion, and the scores were averaged.

\section{Measurement of mtDNA content}

MtDNA content of each sample at $12 \mathrm{~h}$ after transient ischemia was determined as described previously [31]. Briefly, total genomic DNA (gDNA) was isolated from retinas by using DNeasy ${ }^{\circledR}$ Blood \& Tissue Kit (Qiagen, Valencia, CA, USA) as described in the manufacturer's protocol. For the measurement of relative mtDNA content, real-time PCR was carried out using MX3000P real-time PCR system (Stratagene, La Jolla, CA, USA) as following. Total gDNAs $(10 \mathrm{ng})$ from the each sample were amplified using iQTM SYBR ${ }^{\circledR}$ Green supermix (Bio-Rad, Hercules, $\mathrm{CA}, \mathrm{USA}$ ) and mitochondrial cytocrome B (CytB-F:
5'-GGTCTTTTCTTAGCCATACACTACA-3'; CytB-R: $5^{\prime}$-ATATCGGATTAGTCACCCGTAAT- $3^{\prime}$ ) or $\beta$-actin (ActBF; GATCGATGCCGGTGCTAAGA-3'; ActB-R: 5'-CAC CATCACACCCTGTGGAAG-3') primers for 40 cycles [initial incubation at $95{ }^{\circ} \mathrm{C}$ for $10 \mathrm{~min}$, and 40 cycles $\left(95{ }^{\circ} \mathrm{C}\right.$ for $30 \mathrm{~s}, 55^{\circ} \mathrm{C}$ for $30 \mathrm{~s}$ and $72{ }^{\circ} \mathrm{C}$ for $20 \mathrm{~s}$ )]. Output data were obtained as $\mathrm{Ct}$ values and the difference of mtDNA content among samples was calculated using the comparative $\mathrm{Ct}$ method [32]. ActB gene was used to normalize the ratio between mtDNA and gDNA. The samples were run in triplicates for all experiment.

Statistical analysis

Data were presented as the mean \pm SD. Comparison of two or three experimental conditions was evaluated using the unpaired, two-tailed Student's $t$ test or one-way analysis of variance and the Bonferroni $t$ test. $P<0.05$ was considered to be statistically significant.

\section{Results}

The effect of $\mathrm{CoQ}_{10}$ in IOP and body weight

We began either unsupplemented control or $\mathrm{CoQ}_{10}(1 \%)$ supplemented diet treatment daily for 1 week before the induction of transient retinal ischemia and then continued diet treatment for 2 weeks (Fig. 1a). Transient retinal ischemia was induced by acute IOP elevation to $71.8 \pm 4.0 \mathrm{mmHg}$ in mice treated with control diet ( $n=30$ mice) and $70.3 \pm 5.0 \mathrm{mmHg}$ in mice treated with $\mathrm{CoQ}_{10}$ diet ( $n=30$ mice) for $50 \mathrm{~min}$ (Fig. 1b). The pressure was enough to induce retinal ischemia and the phenotype was similar to pathologic acute angle closure glaucoma because when IOP reached $60 \mathrm{mmHg}$, the retina flow rate decreased by $68 \%$ for retinal artery in rodent model [5, 33, 34]. The mean IOP of contralateral control eyes was $8.4 \pm 0.7 \mathrm{mmHg} \quad(n=20$ mice; Fig. 1b). In addition, no difference was found in body weight between control and $\mathrm{CoQ}_{10}$ diet-treated mice during experimental period ( $n=20$ or 30 mice; Fig. 1b).

$\mathrm{CoQ}_{10}$ ameliorates oxidative stress in ischemic retina

We determined whether $\mathrm{CoQ}_{10}$ treatment prevents oxidative stress-mediated upregulation of superoxide dismutase 2 (SOD2) and heme oxygenase-1 (HO-1) protein expression using antibodies raised against SOD2 and HO-1. We observed that Increase of SOD2 protein expression was maximal $12 \mathrm{~h}$ later by $1.36 \pm 0.04$-fold in ischemic retina $(P<0.05$; Fig. 2a). The relative quantity of SOD2 protein expression was less at $24 \mathrm{~h}$ than at $12 \mathrm{~h}$ after 


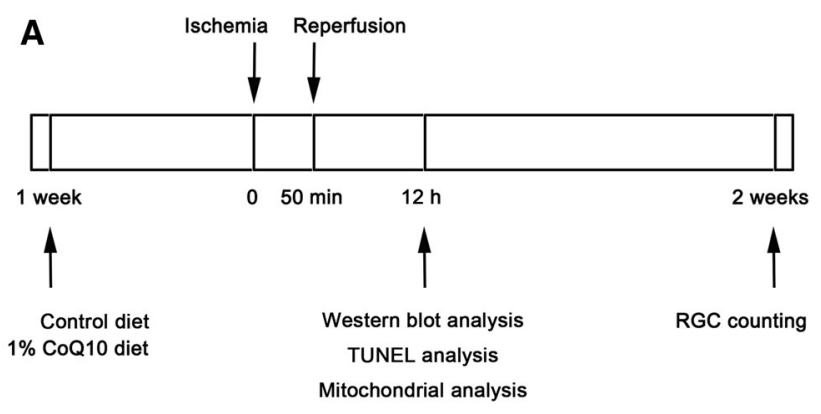

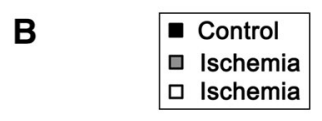

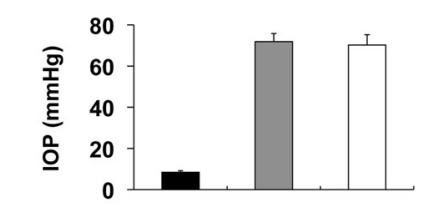

Control diet $1 \%$ CoQ10 diet

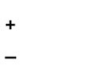

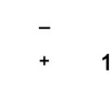

Fig. $1 \mathrm{CoQ}_{10}$ supplementation and induction of transient retinal ischemia. a Diagram for control and $\mathrm{CoQ}_{10}(1 \%)$ supplementation before and after ischemic injury. Unsupplemented control or $\mathrm{CoQ}_{10}$ diet were daily treated for 1 week before the induction of transient retinal ischemia and continued for 2 weeks. b IOP elevation in the mouse eyes and body weight in control diet- and $\mathrm{CoQ}_{10}$ diet-treated mice following transient retinal ischemic injury

ischemia-reperfusion. Intriguingly, $\mathrm{CoQ}_{10}$ treatment preserved SOD2 and HO-1 protein expression in ischemic retina at $12 \mathrm{~h}$ compared with control diet-treated ischemic retina $(P<0.05$; Fig. $2 b)$, indicating that $\mathrm{CoQ}_{10}$ ameliorates oxidative stress in ischemic retinal injury.

\section{$\mathrm{CoQ}_{10}$ promotes RGC survival in ischemic retina}

Since $\mathrm{CoQ}_{10}$ is neuroprotective against retinal damage by high IOP-induced transient ischemic injury and other apoptotic insults $[35,36]$, we determined whether $\mathrm{CoQ}_{10}$ promotes RGC survival in ischemic retina using wholemount immunohistochemistry for Brn3a, a marker for RGCs. Mean RGC density per retina for each group is presented in Supplementary Table 1. Non-ischemic control mouse retina had an average of $3329 \pm 533$ RGCs in the central, $3326 \pm 446$ RGCs in the middle and $2230 \pm 420$ RGCs in the peripheral areas ( $n=7$ retinas) (Fig. 3a, b; Supplementary Table 1). In comparison with non-ischemic control retina treated with control diet, control diet treatment showed about $32 \%$ of RGC loss in ischemic retina $(P<0.01$; Fig. 3a, b; Supplementary Table 1$)$. In contrast, $\mathrm{CoQ}_{10}$ significantly promoted RGC survival by an approximate $21 \%$ compared with control diet-treated ischemic retina $(P<0.05$; Fig. 3a, b; Supplementary

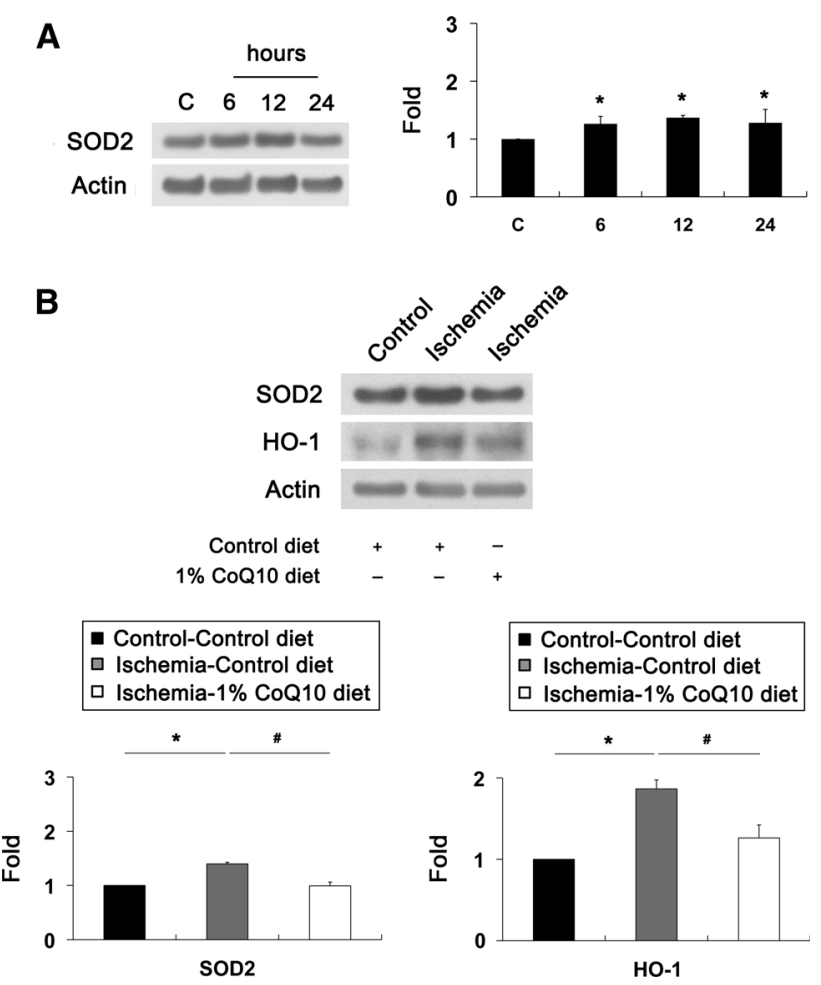

Fig. $2 \mathrm{CoQ}_{10}$-mediated blockade of oxidative stress in ischemic injury. Unsupplemented control or $\mathrm{CoQ}_{10}(1 \%)$ diet were daily treated for 1 week before the induction of transient retinal ischemia and continued for 6,12 or $24 \mathrm{~h}$. a SOD2 Western blot analyses at 6 , 12 and $24 \mathrm{~h}$ after transient retinal ischemia. Increase of SOD2 protein expression was maximal at $12 \mathrm{~h}$ in ischemic retina. The relative expression level of SOD2 protein was less at $24 \mathrm{~h}$ than at $12 \mathrm{~h}$ after ischemia-reperfusion. b SOD2 and HO-1 Western blot analyses at $12 \mathrm{~h}$ after transient retinal ischemia. $\mathrm{CoQ}_{10}$ treatment preserved SOD2 and HO-1 protein expression in ischemic retina compared with control diet-treated ischemic retina. Values are mean $\pm \mathrm{SD}(n=3$ retinas/group). *Significant at $P<0.05$ compared with control-diettreated non-ischemic contralateral control retina or "Significant at $P<0.05$ compared with control diet-treated ischemic retina. SOD2 superoxide dismutase 2, $\mathrm{HO}-1$ hemeoxygenase-1

Table 1). Astroglial and/or microglial activation coincide with RGC degeneration in the hypertensive retina of human, rat or mouse $(3,37-39)$. To investigate whether $\mathrm{CoQ}_{10}$ blocks the activation of astroglial and microglial cells in ischemic retina, we performed whole-mount immunohistochemistry or Western blot analyses using antibodies raised against glial fibrillary acidic protein (GFAP), a marker for astroglial cells, or Iba1, a marker for microglial cells. We found that GFAP and Iba1 immunoreactivity were increased in activated astroglia and microglial cells in the GCL and nerve fiber layer of control diet-treated ischemic retina at $12 \mathrm{~h}$, respectively (Fig. 4a). Further, astroglial and microglial activation are accompanied by RGC loss as indicated by significantly increased GFAP and Iba- 1 protein expression by $2.89 \pm 0.49$ - and $11.8 \pm 2.59$-fold in control diet-treated ischemic retina at 


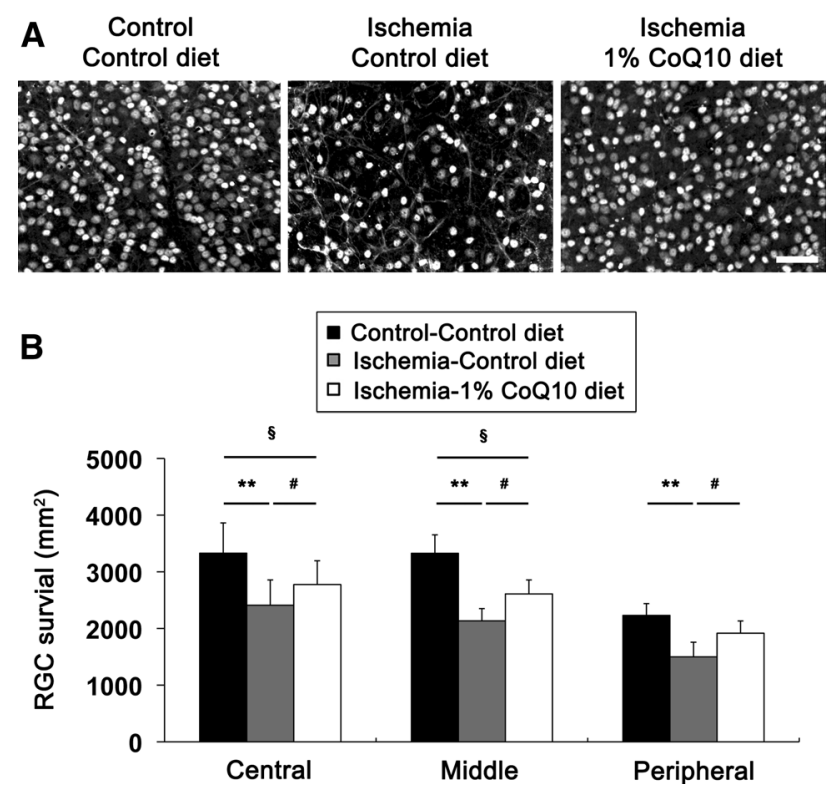

Fig. $3 \mathrm{CoQ}_{10}$-mediated protection of RGC survival in ischemic retina. Unsupplemented control or $\mathrm{CoQ}_{10}(1 \%)$ diet were daily treated for 1 week before the induction of transient retinal ischemia and continued for 2 weeks. a Brn3a whole-mount immunohistochemistry at 2 weeks after transient retinal ischemia. High magnification showed representative images from the middle area of retinas. b Quantitative analysis of RGC survival. Values are mean $\pm \mathrm{SD}$ ( $n=7$ retinas/group). ${ }^{s}$ Significant at $P<0.05$ and $* *$ Significant at $P<0.01$ compared with control diet-treated non-ischemic control retina or ${ }^{\text {\# }}$ Significant at $P<0.05$ compared with control diet-treated ischemic retina. Scale bar $50 \mu \mathrm{m}$

$12 \mathrm{~h}$, respectively $(P<0.05$ for GFAP and $P<0.01$ for Iba-1; Fig. 4b). In contrast, $\mathrm{CoQ}_{10}$ significantly decreased GFAP and Iba- 1 protein expression by $2.00 \pm 0.23$ - and $1.38 \pm 0.77$-fold in ischemic retina at $12 \mathrm{~h}$ compared with control diet-treated ischemic retina $(P<0.05$ for GFAP and $P<0.01$ for Iba-1; Fig. 4b), indicating that $\mathrm{CoQ}_{10}$ prevents activation of astroglial and microglial cells in ischemic retina by blocking oxidative stress. In addition, there were no significant changes in RGC survival and GFAP protein expression between control- and $\mathrm{CoQ}_{10^{-}}$ treated control mice (Supplementary Fig. 1 and Supplementary Table 2).

$\mathrm{CoQ}_{10}$ blocks apoptotic cell death by decreasing Bax or by increasing pBad protein expression in ischemic retina

To determine whether $\mathrm{CoQ}_{10}$ prevents apoptotic cell death in ischemic retina, we performed TUNEL staining. There were no TUNEL-positive cells in the retina of control mice treated control diet (Fig. 5a, b). However, ischemic retinas showed TUNEL-positive apoptotic cell death in the inner nuclear layer $(58 \pm 10$ per $\mathrm{mm})$ and GCL $(99 \pm 18$ per $\mathrm{mm}$ ) at $12 \mathrm{~h}$ (Fig. 5a, b). In contrast, there were no
TUNEL-positive cells in ischemic retina treated $\mathrm{CoQ}_{10}$ diet (Fig. 5a, b). In comparison with control diet-treated nonischemic control retina, control diet-treated ischemic retina showed a significant induction of cleaved caspase- 3 protein expression at $12 \mathrm{~h}$ by $2.68 \pm 0.29$-fold $(P<0.01$; Fig. 5c). However, $\mathrm{CoQ}_{10}$ significantly reduced cleaved caspase- 3 protein expression at $12 \mathrm{~h}$ by $0.98 \pm 0.21$-fold in ischemic retina $(P<0.01$; Fig. 5 c $)$.

Our previous study showed that ischemic injury induces a significant increase of Bax and pBad protein expression in the early apoptotic pathway-mediated neurodegeneration of rat retina [5]. To determine whether $\mathrm{CoQ}_{10}$ modulates apoptotic cell death pathway in ischemic retina, we performed Western blot analysis using antibodies for Bax and pBad. We found that Bax protein expression was significantly increased by $2.71 \pm 0.25$-fold in ischemic retina at $12 \mathrm{~h}$ compared with control diet-treated non-ischemic control retina $\left(P<0.01\right.$; Fig. 6). In contrast, $\mathrm{CoQ}_{10}$ significantly decreased Bax protein expression by $1.61 \pm 0.15$-fold in ischemic retina at $12 \mathrm{~h}$ compared with control diet-treated ischemic retina $(P<0.01$; Fig. 6$)$. pBad protein expression was significantly increased by $8.02 \pm 0.56$-fold in ischemic retina at $12 \mathrm{~h}$ compared with control diet-treated non-ischemic control retina $(P<0.01$; Fig. 6). Intriguingly, $\mathrm{CoQ}_{10}$ showed greater increase of pBad protein expression by $9.31 \pm 0.39$-fold in ischemic retina at $12 \mathrm{~h}$ compared with control diet-treated ischemic retina $(P<0.05$; Fig. 6$)$, suggesting that $\mathrm{CoQ}_{10}$ protects RGCs against oxidative stress-mediated apoptotic cell death by decreasing Bax or by increasing pBad protein expression in ischemic retina.

\section{$\mathrm{CoQ}_{10}$ preserves $\mathrm{Tfam}$ protein expression in ischemic} retina

To determine whether oxidative stress induced by acute IOP elevation alters mtDNA content and whether $\mathrm{CoQ}_{10}$ preserves this alteration in ischemic retina, mtDNA content was determined by real-time PCR analysis. We found that there were no differences in mtDNA content among control diet-treated non-ischemic control, and control diet-treated ischemic and $\mathrm{CoQ}_{10}$-treated ischemic retinas at $12 \mathrm{~h}$ (Fig. 7a). Oxidative stress triggers increase of Tfam protein expression in ischemic rat retina [5]. To determine whether $\mathrm{CoQ}_{10}$ preserves this alteration in ischemic retina, we examined the expression level of Tfam using Western blot analysis. We observed that Increase of Tfam protein expression was maximal $12 \mathrm{~h}$ later by $1.86 \pm 0.12$-fold in ischemic retina $(P<0.05$; Fig. $7 b)$. The relative expression level of Tfam protein was less at $24 \mathrm{~h}$ than at $12 \mathrm{~h}$ in ischemic retina. Intriguingly, $\mathrm{CoQ}_{10}$ treatment partially preserved Tfam protein expression at $12 \mathrm{~h}$ compared with control diet-treated ischemic retina $(P<0.05$; Fig. $7 \mathrm{c})$. 
Fig. $4 \mathrm{CoQ}_{10}$-mediated blockade of astroglial and microglial activation in ischemic retina.

Unsupplemented control or $\mathrm{CoQ}_{10}(1 \%)$ diet were daily treated for 1 week before the induction of transient retinal ischemia and continued for 12 h. a Double immunohistochemistry for GFAP and Iba- 1 at $12 \mathrm{~h}$ after transient retinal ischemia. Control diet-treated Ischemic retina increased GFAP and Iba1 immunoreactivites in the GCL compared with control diettreated non-ischemic control retina. In contrast, $\mathrm{CoQ}_{10}$ treatment decreased GFAP and Iba1 immunoreactivities in the GCL of ischemic retina. Intriguingly, higher magnification showed a quiescent microglial cell that has ramified long and thin processes in control diet-treated non-ischemic control retina and $\mathrm{CoQ}_{10}$ diet-treated ischemic retina (arrowheads). However, control diet-treated ischemic retina showed an activated microglial cell that has thickened processes (arrowheads) and swollen cell body (arrow). GCL ganglion cell layer. Scale bars $50 \mu \mathrm{m}$. b GFAP and Iba- 1 Western blot analyses at $12 \mathrm{~h}$ after transient retinal ischemia. Control diettreated ischemic retina significantly increased GFAP and Iba- 1 protein expression compared with control diettreated non-ischemic control retina. However, $\mathrm{CoQ}_{10}$ treatment significantly decreased GFAP and Iba-1 protein expression in ischemic retina. Values are mean $\pm \mathrm{SD}$ ( $n=3$ retinas/group).

*, ${ }^{8}$ Significant at $P<0.05$ and

**Significant at $P<0.01$ compared with control diettreated non-ischemic control retina or "Significant at $P<0.05$ and ${ }^{\# \#}$ Significant at $P<0.01$ compared with control diet-treated ischemic retina
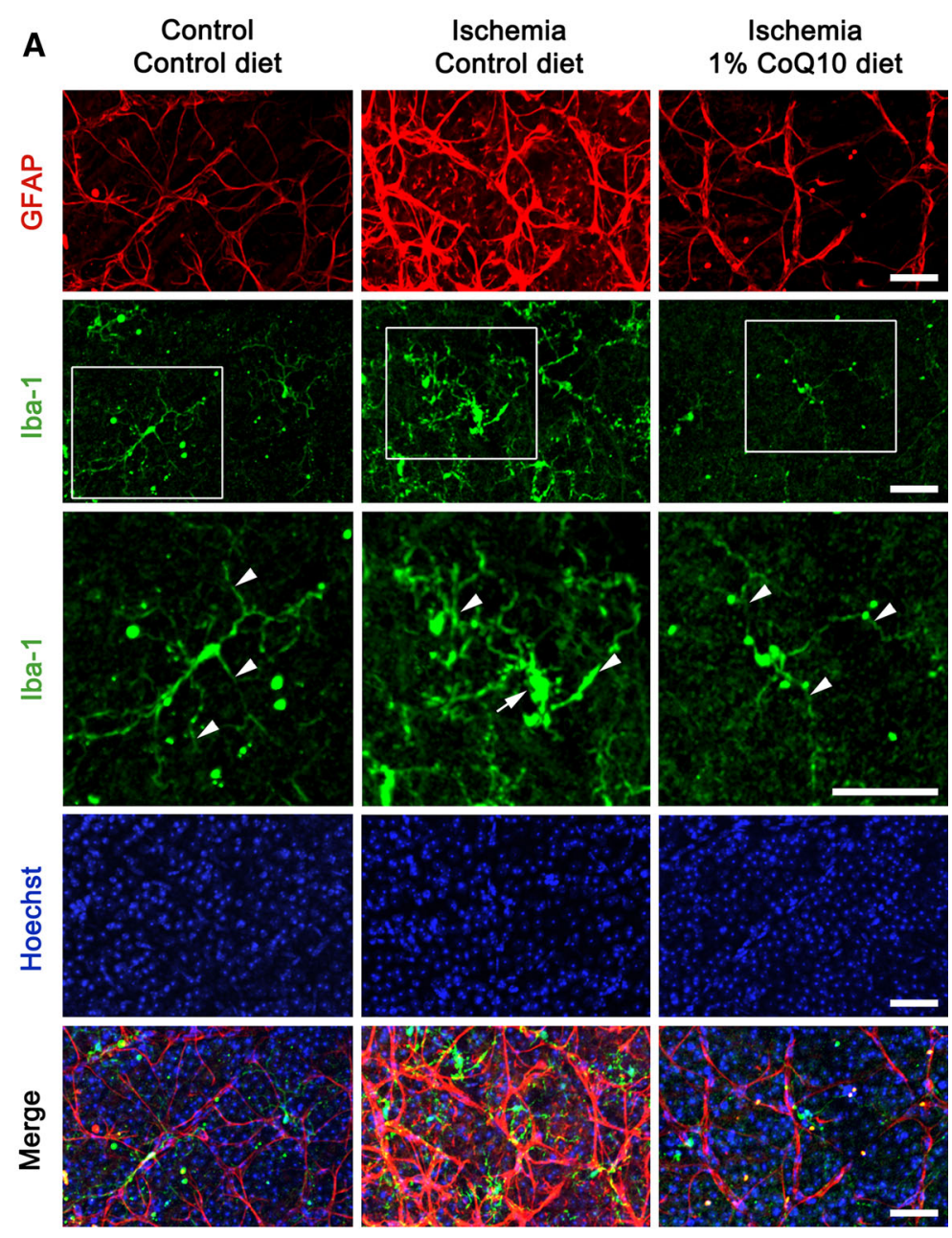

B
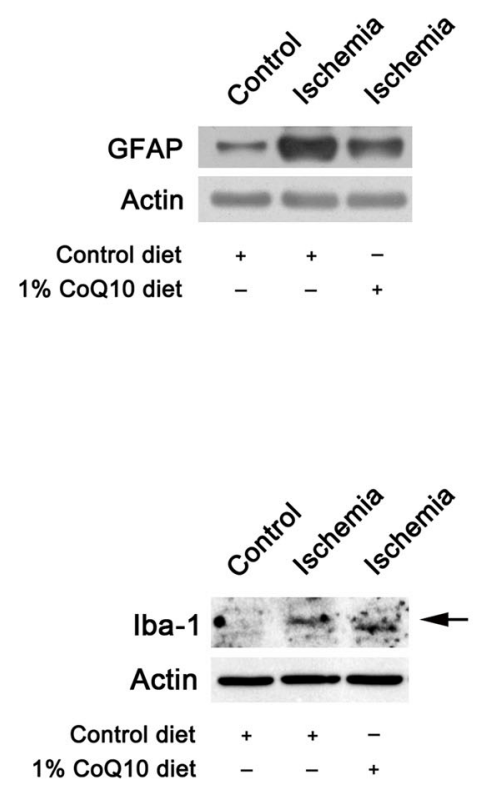

- Control-Control diet

I Ischemia-Control diet

口 Ischemia-1\% CoQ10 diet

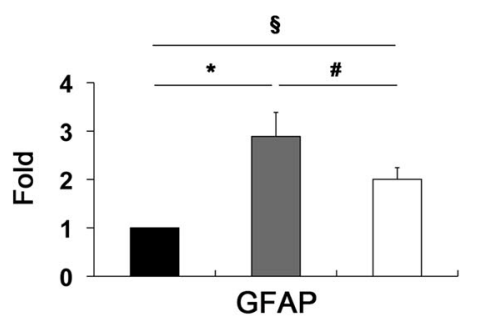

GFAP

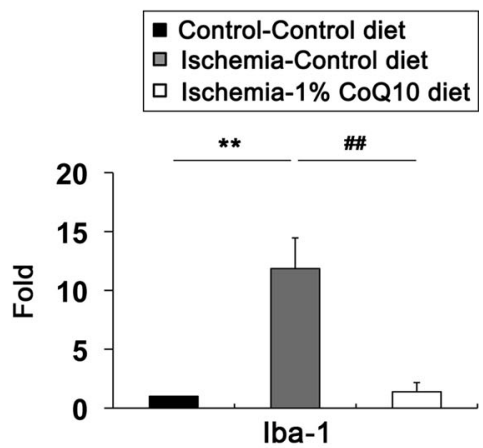




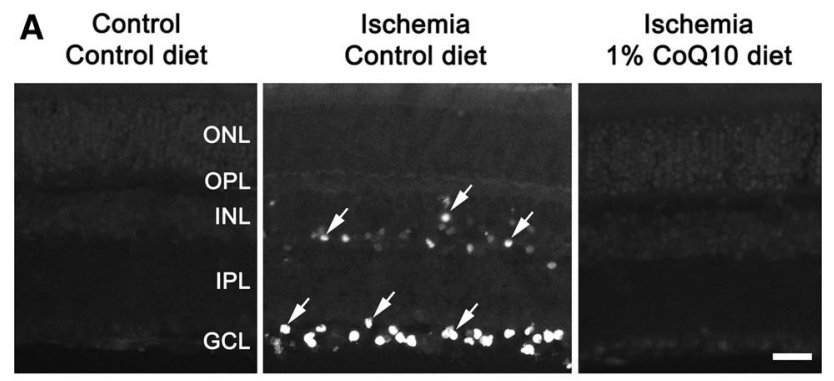

B

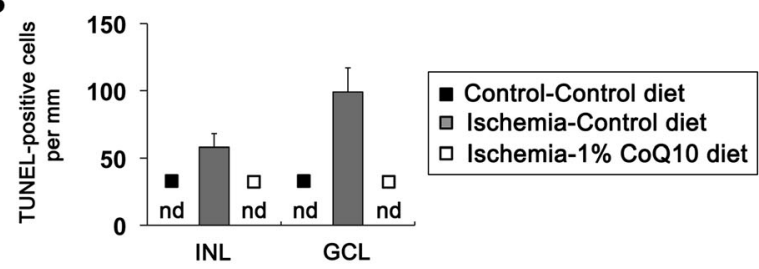

C

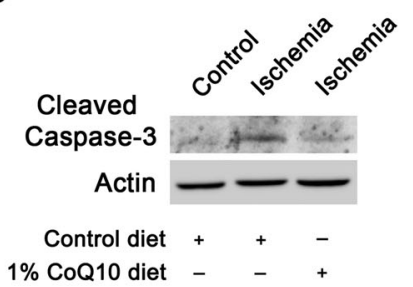

- Control-Control diet

$\square$ Ischemia-Control diet

Ischemia-1\% CoQ10 diet

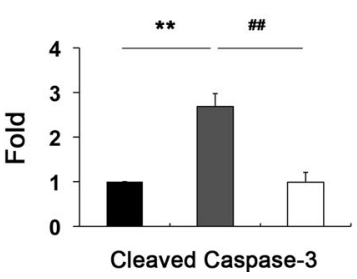

Fig. $5 \mathrm{CoQ}_{10}$-mediated blockade of apoptotic cell death in ischemic retina. Unsupplemented control or $\mathrm{CoQ}_{10}(1 \%)$ diet daily were daily treated for 1 week before the induction of transient retinal ischemia and continued for $12 \mathrm{~h}$. a TUNEL staining at $12 \mathrm{~h}$ after transient retinal ischemia. There were no TUNEL-positive cells in the GCL and INL of control diet-treated non-ischemic retina. However, control diet-treated ischemic retina showed TUNEL-positive apoptotic cell death in the GCL and INL at $12 \mathrm{~h}$ (arrows). In contrast, there were no TUNEL-positive cells in $\mathrm{CoQ}_{10}$ diet-treated ischemic retina. INL inner nuclear layer, $I P L$ inner plexiform layer, $G C L$ ganglion cell layer, $n d$ non-detectable, $O N L$ outer nuclear layer, $O P L$ outer plexiform layer. Scale bar $20 \mu \mathrm{m}$. b Quantitative analysis of TUNEL-positive cells at $12 \mathrm{~h}$ after transient retinal ischemia. Values are mean $\pm \mathrm{SD}$ ( $n=5$ retinas/group). c Caspase-3 Western blot analysis at $12 \mathrm{~h}$ after transient retinal ischemia. Control diet-treated ischemic retina significantly increased induction of cleaved caspase- 3 protein expression compared with control diet-treated non-ischemic control retina. In contrast, $\mathrm{CoQ}_{10}$ treatment significantly decreased cleaved caspase-3 protein expression in ischemic retina compared with control diet-treated ischemic retina. Values are mean \pm SD ( $n=3$ retinas/group). **Significant at $P<0.01$ compared with control diet-treated non-ischemic control retina or ${ }^{\# \#}$ Significant at $P<0.01$ compared with control diet-treated ischemic retina

However, there was no difference in expression level of porin protein between control diet- and $\mathrm{CoQ}_{10}$ diet-treated ischemic retina. These results suggest that oxidative stress induced by acute IOP elevation increases Tfam protein expression but shows no alteration of mtDNA content in ischemic retina.

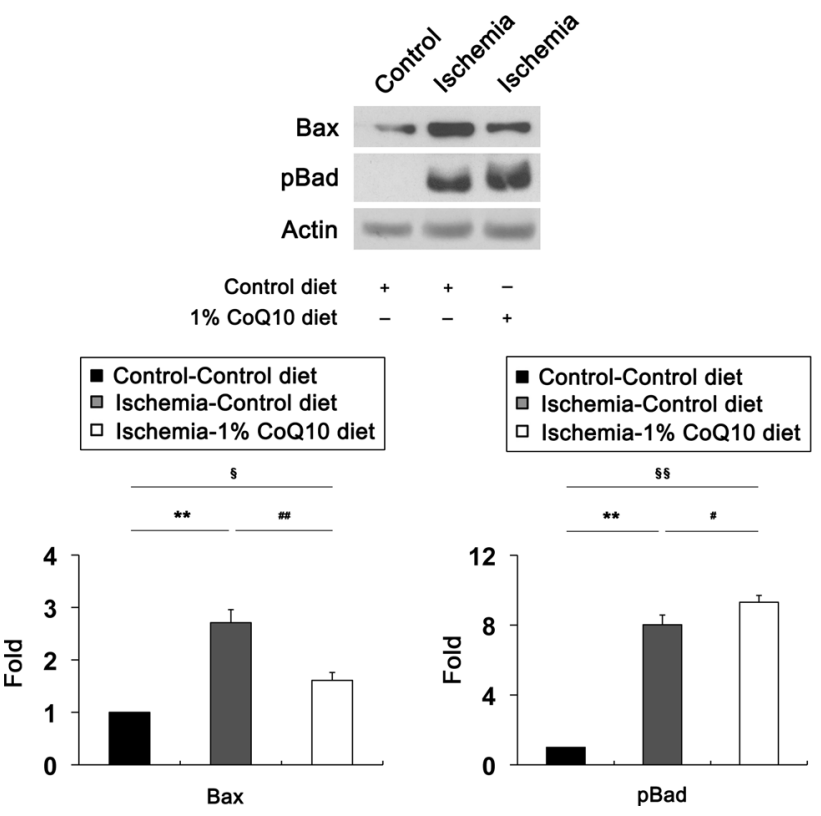

Fig. $6 \mathrm{CoQ}_{10}$-mediated blockade of apoptotic pathway in ischemic retina. Unsupplemented control or $\mathrm{CoQ}_{10}(1 \%)$ diet were daily treated for 1 week before the induction of transient retinal ischemia and continued for $12 \mathrm{~h}$. Bax and pBad Western blot analyses at $12 \mathrm{~h}$ after transient retinal ischemia. Control diet-treated ischemic retina significantly increased $\mathrm{Bax}$ and $\mathrm{pBad}$ protein expression. In contrast, $\mathrm{CoQ}_{10}$ treatment significantly decreased Bax protein expression, but increased $\mathrm{pBad}$ protein expression in ischemic retina compared with control diet-treated ischemic retina. Values are mean $\pm \mathrm{SD}(n=3$ retinas/group). ${ }^{\delta}$ Significant at $P<0.05$ and $* *,{ }^{\S}$ Significant at $P<0.01$ compared with control diet-treated non-ischemic control retina or ${ }^{\#}$ Significant at $P<0.05$ and ${ }^{\# \#}$ Significant at $P<0.01$ compared with control diet-treated ischemic retina. $p B a d$ phosphorylated Bad

\section{Discussion}

$\mathrm{CoQ}_{10}$ is an attractive neurotherapeutic agent for retinal protection against high IOP elevation-induced oxidative stress in retinal ischemic injury $[24,25]$ as well as other neurodegenerative diseases including Parkinson' and Huntington's diseases [20, 26, 40-42]. Moreover, $\operatorname{CoQ}_{10}$ is neuroprotective in retinal cells in vivo and in vitro against oxidative stress and excitotoxicity [23, 35, 41]. It has been reported that that $\mathrm{CoQ}_{10}$ supplements correlated with plasma $\mathrm{CoQ}_{10}$ level and $\mathrm{CoQ}_{10}$ in large doses was taken up all tissues including heart and brain mitochondria [43], suggesting that $\mathrm{CoQ}_{10}$ could also be taken up by retina and lead to a beneficial effect in ischemic retina injury. In support of this notion, a recent study demonstrated that oral supplementation of $\mathrm{CoQ}_{10}$ was neuroprotective against retinal damage induced by intravitreal injection of $\mathrm{N}$-methyl-d-aspartate in mice in vivo [23]. In the current study, we addressed the question of whether a $\mathrm{CoQ}_{10^{-}}$ supplemented diet inhibits oxidative stress-mediated 


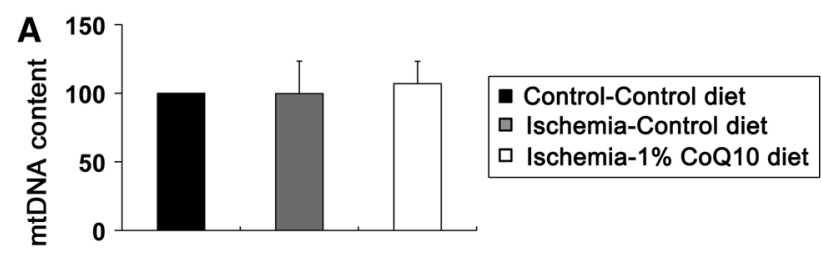

B

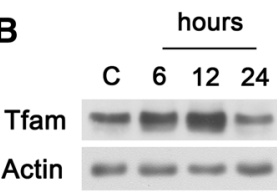

C

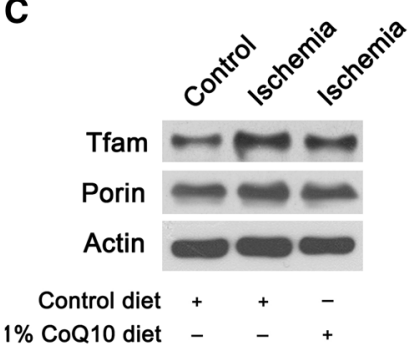

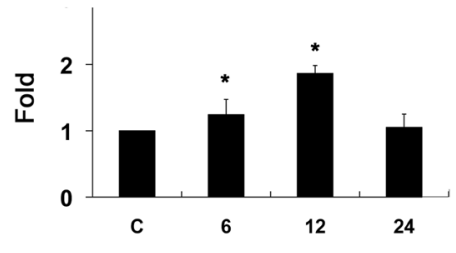

- Control-Control diet $\square$ Ischemia-Control diet 口 Ischemia-1\% CoQ10 diet

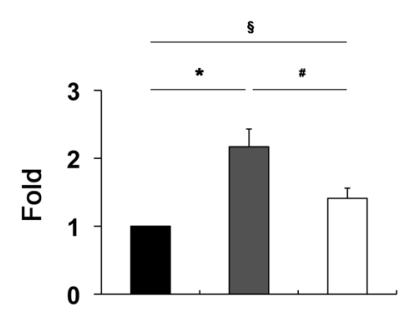

Fig. $7 \mathrm{CoQ}_{10}$-mediated restoration of Tfam protein expression in ischemic retina. Unsupplemented control or $\mathrm{CoQ}_{10}(1 \%)$ diet were daily treated for 1 week before the induction of transient retinal ischemia and continued for $12 \mathrm{~h}$. a mtDNA content at $12 \mathrm{~h}$ after transient retinal ischemia. Real-time PCR analysis showed that there were no differences in mtDNA content among groups. (b, and c) Tfam Western blot analysis at $12 \mathrm{~h}$ after transient retinal ischemia. b Tfam Western blot analyses at 6,12 and $24 \mathrm{~h}$ after transient retinal ischemia. Increase of Tfam protein expression was maximal at $12 \mathrm{~h}$ in control diet-treated ischemic retina. The relative concentration of Tfam protein expression was less at $24 \mathrm{~h}$ than at $12 \mathrm{~h}$ after ischemiareperfusion. c Tfam Western blot analysis at $12 \mathrm{~h}$ after transient retinal ischemia. $\mathrm{CoQ}_{10}$ treatment preserved $\mathrm{Tfam}$ protein expression at $12 \mathrm{~h}$ in ischemic retina compared with control diet-treated ischemic retina. Values are mean $\pm \mathrm{SD}\left(n=3\right.$ retinas/group). ${ }^{*}{ }^{s}$ Significant at $P<0.05$ compared with control diet-treated non-ischemic control retina or " Significant at $P<0.05$ compared with control diet-treated ischemic retina. Tfam mitochondrial transcription factor A, $m t D N A$ mitochondrial DNA

mitochondrial dysfunction and RGC degeneration in ischemic retina.

We previously reported that acute IOP elevation triggers the upregulation of SOD2 protein expression and this increase could be restored by brimonidine (BMD)-mediated blockade of glutamate excitotoxicity-induced oxidative stress in ischemic rat retina [5]. Consistent with these results, we have now found that the upregulation of SOD2 and $\mathrm{HO}-1$ protein expression by acute IOP elevation was maximal early the neurodegeneration $(12 \mathrm{~h})$ of retinal ischemia. However, $\mathrm{CoQ}_{10}$ treatment decreases SOD2 and HO-1 protein expression in ischemic retina. Endogenous antioxidants such as mitochondrial SOD2 that localizes in the mitochondrial matrix and catalyzes the dismutation of superoxide radicals normally regulate ROS generated in mitochondria [44, 45]. It has been reported that SOD2 expression is increased by the stimulation of mitochondrial superoxide anion $\left(\mathrm{O}_{2}^{-}\right)$[46] and $\mathrm{CoQ}_{10}$ treatment could reduce the $\mathrm{O}_{2}{ }^{-}$production [47]. Growing evidence indicates that overexpression of the SOD2 gene inhibits retinal damage by reducing oxidative stress and nitrosative stress [48], as well as protecting retinal vascular cells and capillary degeneration against apoptotic cell death in mouse models of ischemic injury [49]. Moreover, the upregulation of SOD2 is accompanied by a higher resistance to oxidative stress as well as SOD2 activity directly stabilizing mitochondrial transmembrane potential and calcium buffering ability $[50,51]$. Our results, therefore, raise the possibility that increasing SOD2 or HO-1 expression in retinal ischemic injury may contribute to compensatory endogenous antioxidant mechanisms that increase resistance or stabilization of mitochondria against acute IOP elevation-induced oxidative stress. Taken together, it is noteworthy that these results suggest that $\mathrm{CoQ}_{10}$ could be an important antioxidant for ameliorating oxidative stress-mediated neurodegeneration in ischemic retina. Studying the benefits of $\mathrm{CoQ}_{10^{-}}$ mediated blockade of oxidative stress or enhancement of antioxidant enzymes may be a novel strategy for protecting retinal neurons against ischemic injury.

In the current study, we observed that $\mathrm{CoQ}_{10}$ treatment significantly promoted RGC survival as well as blocked activation of astroglial and microglial cells in ischemic retina. Astroglial or microglial activation coincides with RGC degeneration in the hypertensive retina of human, rat or mouse $[3,5,37-39]$. Thus, it is possible that $\mathrm{CoQ}_{10}$-mediated blockade of oxidative stress may indirectly reduce astroglial or microglial activation in the retina against elevated IOP-induced ischemic damage as a result of increased RGC survival. Regardless, it cannot be excluded that $\mathrm{CoQ}_{10}$ may prevent glial activation by blocking oxidative stress in astroglial or microglial cells in ischemic retina. $\mathrm{CoQ}_{10}$ is also neuroprotective in retinal glial cells against oxidative stress, since oxidative stress has remarkably linked to glial cell activation or reaction in the retina or optic nerve still needs to be ascertained [5, 52-56]. In addition, interestingly, it has been reported that IOP induced the upregulation of GFAP and major histochompatibility complex class II molecule, as well as of microglial activity in the controlateral control retinas in experimental rodent models of glaucoma induced by laser treatment [57, 58]. Although there was no evidence of glial activation in the contralateral nonischemic control retina in the current study, future studies will need to clarify to use contralateral retina as an internal control in our ischemic model of mice.

Consistent with our result that $\mathrm{CoQ}_{10}$ promoted RGC survival in ischemic retina, we found that $\mathrm{CoQ}_{10}$ significantly decreased Bax, but increased pBad protein expression in ischemic retina. $\mathrm{Bax}$ is a pro-apoptotic member of the $\mathrm{Bcl}-2$ 
family that is essential in many apoptotic pathways $[59,60]$ as well as directly interacts with the component forming the mitochondrial permeability transition pore (MPTP) that allows proteins to escape from the mitochondria into the cytosol to initiate apoptosis [61-63]. Bax is counteracted by $\mathrm{Bcl}-\mathrm{xL}$ that forms heterodimers with dephosphorylation of $\mathrm{Bad}$, which inactivates $\mathrm{Bcl}-\mathrm{xL}$; and pBad eliminates this dimerization, which activates Bcl-xL [64, 65]. Our collective results suggest that $\mathrm{CoQ}_{10}$ promotes $\mathrm{RGC}$ survival against the mitochondria-related apoptotic pathway in ischemic retinal injury by decreasing Bax, but by increasing pBad protein expression. These results reflect the possibility that increased pBad expression may represent an endogenous repair mechanism against apoptotic pathway and that $\mathrm{CoQ}_{10}$ may contribute to the blockade of Bax-mediated increase of MPT or the promotion of mitochondrial homeostasis in ischemic injury. The MPTP opening leads to loss of mitochondrial membrane potential, mitochondrial swelling, rupture of the outer mitochondrial membrane and release of cytochrome $\mathrm{c}$. Importantly, MPTP opening by calcium overload and oxidative stress leads to necrosis rather than apoptosis [66, 67]. Recently, MPTP-mediated neuronal cell death has been implicated as an important pathophysiological mechanism for mitochondrial dysfunction in ischemic injury [24, 25]. Taken together, out findings suggest that $\mathrm{CoQ}_{10}$ may promote RGC survival by inhibiting not only apoptosis but also necrosis in ischemic retinal injury.

Ischemic injury triggers mitochondrial dysfunction including ROS induction as well as mtDNA damage, Tfam alteration or OXPHOS impairment in the central nervous system $[5,19,68]$. Recently, we have reported that acute IOP elevation significantly increased Tfam/OXPHOS complex protein expression and that blockade of glutamate excitotoxicity-induced oxidative stress by BMD treatment preserved Tfam/OXPHOS complex protein expression in ischemic retina [5], suggesting that the preservation of Tfam/OXPHOS complex may provide therapeutic potential for protecting RGCs against mitochondrial dysfunction induced by glutamate excitotoxicity and/or oxidative stress in ischemic retina [5]. In the current study, we observed that retinal ischemic injury triggers significant increase of Tfam protein expression in the early neurodegenerative events (6-12 h) and $\mathrm{CoQ}_{10}$ decreases Tfam protein expression in ischemic retina at $12 \mathrm{~h}$. Emerging evidence suggests that the Tfam and OXPHOS complex IV are rapidly increased in the early neurodegenerative events of neonatal hypoxic-ischemic brain injury, suggesting that Tfam may contribute to endogenous repair mechanism of injured brain neurons [19]. Further, recent studies reported that overexpression of Tfam protects mitochondria against $\beta$-amyloid-induced oxidative damage in human SH-SY5Y neuroblastoma cells and ameliorates delayed neuronal cell death in the hippocampus following transient forebrain ischemia in mice [16, 17]. In contrast, in mice lacking Tfam there is impaired mtDNA transcription and mtDNA loss is triggered; this leads to mitochondrial bioenergetic dysfunction-mediated embryonic lethality [12].

Based on these results, we suggest that $\mathrm{CoQ}_{10}$-mediated preservation of Tfam expression may provide a potential mechanism for protecting RGCs against oxidative stressinduced mitochondrial dysfunction in ischemic retina. Future studies will examine the precise molecular mechanism underlying $\mathrm{CoQ}_{10}$-mediated $\mathrm{Tfam}$ preservation in ischemic retina. Although mtDNA is particularly susceptible to oxidative stress [69], it is unknown whether oxidative stress can directly trigger mtDNA alteration in ischemic retina. Interestingly, we found that there was no statistical difference in mtDNA content among control diet- and $\mathrm{CoQ}_{10}$ diet-treated groups. Because it has been reported that Tfam regulates mtDNA copy numbers in mammals and the levels of Tfam correlate with the levels of mtDNA $[15,70]$, our findings that did not show a correlation between Tfam protein expression and mtDNA content raise the possibility that increasing Tfam protein expression may prevent alteration of mtDNA content against oxidative stress in ischemic retina. Regardless, it would be useful to investigate mtDNA alteration on ischemic retina using measurements for 8-hydroxy-2-deoxyguanosine and mitochondrial membrane potential, and future studies need to address this more detail.

In conclusion, these results provide direct evidence that $\mathrm{CoQ}_{10}$ promotes RGC survival in ischemic mouse retina by inhibiting oxidative stress and by blocking the Bax/Badmediated mitochondrial apoptotic pathway. Moreover, $\mathrm{CoQ}_{10}$ also preserves Tfam protein expression in ischemic mouse retina. Based on these observations, we suggest that $\mathrm{CoQ}_{10}$ may provide a promising therapeutic potential for ameliorating oxidative stress-mediated mitochondrial dysfunction in ischemic retinal injury.

Acknowledgments This work was supported, in part, by the National Institute Health Grants EY018658 (WKJ), NCRR P41 RR004050 and P41GM103412-24 (MHE) and P30EY022589 (Vision Research Core Grant), and a fund of Biomedical Research Institute of Chonbuk National University Hospital (DL) and an unrestricted grant from Research to Prevent Blindness (New York, NY, USA).

Conflict of interest The authors declare that they have no conflict of interest.

Open Access This article is distributed under the terms of the Creative Commons Attribution License which permits any use, distribution, and reproduction in any medium, provided the original author(s) and the source are credited.

\section{References}

1. Weinreb RN, Khaw PT (2004) Primary open-angle glaucoma. Lancet 363:1711-1720 
2. Ju WK, Lindsey JD, Angert M, Patel A, Weinreb RN (2008) Glutamate receptor activation triggers OPA1 release and induces apoptotic cell death in ischemic rat retina. Mol Vis 14:2629-2638

3. Park SW, Kim KY, Lindsey JD, Heo H, Nguyen DH, Ellisman $\mathrm{MH}$ et al (2011) A selective inhibitor of drp1, mdivi-1, increases retinal ganglion cell survival in acute ischemic mouse retina. Invest Ophthalmol Vis Sci 52:2837-2843

4. Chan AS, Saraswathy S, Rehak M, Ueki M, Rao NA (2012) Neuroglobin protection in retinal ischemia. Invest Ophthalmol Vis Sci 53:704-711

5. Lee D, Kim KY, Noh YH, Chai S, Lindsey JD, Ellisman MH et al (2012) Brimonidine blocks glutamate excitotoxicity-induced oxidative stress and preserves mitochondrial transcription factor a in ischemic retinal injury. PLoS One 7:e47098

6. Liu Q, Ju WK, Crowston JG, Xie F, Perry G, Smith MA et al (2007) Oxidative stress is an early event in hydrostatic pressure induced retinal ganglion cell damage. Invest Ophthalmol Vis Sci 48:4580-4589

7. Kong YX, Van Bergen N, Trounce IA, Bui BV, Chrysostomou V, Waugh $\mathrm{H}$ et al (2011) Increase in mitochondrial DNA mutations impairs retinal function and renders the retina vulnerable to injury. Aging Cell 10:572-583

8. Oguni M, Tanaka O, Tamura H, Shinohara H, Kato K, Setogawa T (1995) Ontogeny of copper-zinc and manganese superoxide dismutase in the developing rat retina: immunohistochemical and immunochemical study. Ophthalmic Res 27:227-233

9. Fukui M, Zhu BT (2010) Mitochondrial superoxide dismutase SOD2, but not cytosolic SOD1, plays a critical role in protection against glutamate-induced oxidative stress and cell death in HT22 neuronal cells. Free Radic Biol Med 48:821-830

10. Jarrett SG, Lin H, Godley BF, Boulton ME (2008) Mitochondrial DNA damage and its potential role in retinal degeneration. Prog Retin Eye Res 27:596-607

11. Lee S, Van Bergen NJ, Kong GY, Kong GY, Chrysostomou V, Waugh HS et al (2011) Mitochondrial dysfunction in glaucoma and emerging bioenergetic therapies. Exp Eye Res 93:204-212

12. Larsson NG, Wang J, Wilhelmsson H, Oldfors A, Rustin P, Lewandoski $\mathrm{M}$ et al (1998) Mitochondrial transcription factor A is necessary for mtDNA maintenance and embryogenesis in mice. Nat Genet 18:231-236

13. Bonawitz ND, Clayton DA, Shadel GS (2006) Initiation and beyond: multiple functions of the human mitochondrial transcription machinery. Mol Cell 24:813-825

14. Falkenberg M, Larsson NG, Gustafsson CM (2007) DNA replication and transcription in mammalian mitochondria. Annu Rev Biochem 76:679-699

15. Ngo HB, Kaiser JT, Chan DC (2011) The mitochondrial transcription and packaging factor Tfam imposes a U-turn on mitochondrial DNA. Nat Struct Mol Biol 18:1290-1296

16. Xu S, Zhong M, Zhang L, Wang Y, Zhou Z, Hao Y et al (2009) Overexpression of Tfam protects mitochondria against betaamyloid-induced oxidative damage in SH-SY5Y cells. FEBS J 276:3800-3809

17. Hokari M, Kuroda S, Kinugawa S, Ide T, Tsutsui H, Iwasaki Y (2010) Overexpression of mitochondrial transcription factor A (TFAM) ameliorates delayed neuronal death due to transient forebrain ischemia in mice. Neuropathology 30: 401-407

18. Piao Y, Kim HG, Oh MS, Pak YK (2012) Overexpression of TFAM, NRF-1 and myr-AKT protects the MPP(+)-induced mitochondrial dysfunctions in neuronal cells. Biochim Biophys Acta 1820:577-585

19. Yin W, Signore AP, Iwai M, Cao G, Gao Y, Chen J (2008) Rapidly increased neuronal mitochondrial biogenesis after hypoxic-ischemic brain injury. Stroke 39:3057-3063
20. Beal MF, Shults CW (2003) Effects of Coenzyme Q10 in Huntington's disease and early Parkinson's disease. Biofactors 18:153-161

21. McCarthy S, Somayajulu M, Sikorska M, Borowy-Borowski H, Pandey S (2004) Paraquat induces oxidative stress and neuronal cell death; neuroprotection by water-soluble Coenzyme Q10. Toxicol Appl Pharmacol 201:21-31

22. Bessero AC, Clarke PG (2010) Neuroprotection for optic nerve disorders. Curr Opin Neurol 23:10-15

23. Nakajima Y, Inokuchi Y, Nishi M, Shimazawa M, Otsubo K, Hara H (2008) Coenzyme Q10 protects retinal cells against oxidative stress in vitro and in vivo. Brain Res 1226:226-233

24. Russo R, Cavaliere F, Rombola L, Gliozzi M, Cerulli A, Nucci C et al (2008) Rational basis for the development of coenzyme Q10 as a neurotherapeutic agent for retinal protection. Prog Brain Res 173:575-582

25. Nucci C, Tartaglione R, Cerulli A, Mancino R, Spano A, Cavaliere F et al (2007) Retinal damage caused by high intraocular pressure-induced transient ischemia is prevented by coenzyme Q10 in rat. Int Rev Neurobiol 82:397-406

26. Yang L, Calingasan NY, Wille EJ, Cormier K, Smith K, Ferrante RJ et al (2009) Combination therapy with coenzyme Q10 and creatine produces additive neuroprotective effects in models of Parkinson's and Huntington's diseases. J Neurochem 109:1427-1439

27. Ju WK, Misaka T, Kushnareva Y, Nakagomi S, Agarwal N, Kubo $\mathrm{Y}$ et al (2005) OPA1 expression in the normal rat retina and optic nerve. J Comp Neurol 488:1-10

28. Galindo-Romero C, Aviles-Trigueros M, Jimenez-Lopez M, Vallente-Soriano FJ, Sallinas-Navarro M, Nadal-Nicolas F et al (2011) Axotomy-induced retinal ganglion cell death in adult mice: quantitative and topographic time course analyses. Exp Eye Res 92:377-387

29. Galindo-Romero C, Valiente-Soriano FJ, Jimenez-Lopez M, Valiente-Soriano FJ, Salinas-Navarro M, Nadal-Nicolas F et al (2013) Effect of brain-derived neurotrophic factor on mouse axotomized retinal ganglion cells and phagocytic microglia. Invest Ophthalmol Vis Sci 54:974-985

30. Nadal-Nicolas FM, Jimenez-Lopez M, Sobrado-Calvo P, NietoLopex L, Canovas-Martinez I, Salinas-Navarro M et al (2009) Brn3a as a marker of retinal ganglion cells: qualitative and quantitative time course studies in naive and optic nerve-injured retinas. Invest Ophthalmol Vis Sci 50:3860-3868

31. Alavi MV, Bette S, Schimpf S, Schuettauf F, Schraermeyer U, Wehrl HF et al (2007) A splice site mutation in the murine Opa1 gene features pathology of autosomal dominant optic atrophy. Brain 130:1029-1042

32. Schmittgen TD, Livak KJ (2008) Analyzing real-time PCR data by the comparative C(T) method. Nat Protoc 3:1101-1108

33. Zhi Z, Cepurna W, Johnson E, Shen T, Morrison J, Wang RK (2011) Volumetric and quantitative imaging of retinal blood flow in rats with optical microangiography. Biomed Opt Express 2:579-591

34. Ju WK, Kim KY (2011) Measuring glutamate receptor activation-induced apoptotic cell death in ischemic rat retina using the TUNEL assay. Methods Mol Biol 740:149-156

35. Lulli M, Witort E, Papucci L, Torre E, Schipani C, Bergamini C et al (2012) Coenzyme Q10 instilled as eye drops on the cornea reaches the retina and protects retinal layers from apoptosis in a mouse model of kainate-induced retinal damage. Invest Ophthalmol Vis Sci 53:8295-8302

36. Lulli M, Witort E, Papucci L, Torre E, Schiavone N, Dal Monte M et al (2012) Coenzyme Q10 protects retinal cells from apoptosis induced by radiation in vitro and in vivo. J Radiat Res 53:695-703 
37. Tezel G, Chauhan BC, LeBlanc RP, Wax MB (2003) Immunohistochemical assessment of the glial mitogen-activated protein kinase activation in glaucoma. Invest Ophthalmol Vis Sci 44:3025-3033

38. Schuettauf F, Rejdak R, Walski M, Frontczak-Baniewicz M, Voelker M, Blastsios G et al (2004) Retinal neurodegeneration in the DBA/2 J mouse-a model for ocular hypertension. Acta Neuropathol 107:352-358

39. Bosco A, Inman DM, Steele MR, Wu G, Soto I, Marsh-Armstrong $\mathrm{N}$ et al (2008) Reduced retina microglial activation and improved optic nerve integrity with minocycline treatment in the DBA/2 J mouse model of glaucoma. Invest Ophthalmol Vis Sci 49:1437-1446

40. Ferrante RJ, Andreassen OA, Dedeoglu A, Ferrante KL, Jenkins BG, Hersch SM et al (2002) Therapeutic effects of coenzyme Q10 and remacemide in transgenic mouse models of Huntington's disease. J Neurosci 22:1592-1599

41. Guo L, Cordeiro MF (2008) Assessment of neuroprotection in the retina with DARC. Prog Brain Res 173:437-450

42. Li G, Zou L, Jack CR Jr, Yang Y, Yang ES (2007) Neuroprotective effect of Coenzyme Q10 on ischemic hemisphere in aged mice with mutations in the amyloid precursor protein. Neurobiol Aging 28:877-882

43. Bhagavan HN, Chopra RK (2006) Coenzyme Q10: absorption, tissue uptake, metabolism and pharmacokinetics. Free Radic Res 40:445-453

44. Ho YS, Crapo JD (1988) Isolation and characterization of complementary DNAs encoding human manganese-containing superoxide dismutase. FEBS Lett 229:256-260

45. Kasahara E, Lin LR, Ho YS, Reddy VN (2005) SOD2 protects against oxidation-induced apoptosis in mouse retinal pigment epithelium: implications for age-related macular degeneration. Invest Ophthalmol Vis Sci 46:3426-3434

46. Hu Y, Rosen DG, Zhou Y, Feng L, Yang G, Liu J et al (2005) Mitochondrial manganese-superoxide dismutase expression in ovarian cancer: role in cell proliferation and response to oxidative stress. J Biol Chem 280:39485-39492

47. Yokoyama K, Nakamura K, Kimura M, Nomoto K, Itoman M (1999) Effect of coenzyme Q10 on superoxide production in rats with reperfusion injuries. Scand J Plast Reconstr Surg Hand Surg 33:1-5

48. Liu Y, Tang L, Chen B (2012) Effects of antioxidant gene therapy on retinal neurons and oxidative stress in a model of retinal ischemia/reperfusion. Free Radic Biol Med 52:909-915

49. Chen B, Caballero S, Seo S, Grant MB, Lewin AS (2009) Delivery of antioxidant enzyme genes to protect against ischemia/reperfusion-induced injury to retinal microvasculature. Invest Ophthalmol Vis Sci 50:5587-5595

50. Rohl C, Armbrust E, Kolbe K, Lucius R, Maser E, Venz S et al (2008) Activated microglia modulate astroglial enzymes involved in oxidative and inflammatory stress and increase the resistance of astrocytes to oxidative stress in vitro. Glia 56:1114-1126

51. Bruce-Keller AJ, Geddes JW, Knapp PE, McFall RQ, Keller JN, Holtsberg FW et al (1999) Anti-death properties of TNF against metabolic poisoning: mitochondrial stabilization by MnSOD. J Neuroimmunol 93:53-71

52. Malone PE, Hernandez MR (2007) 4-Hydroxynonenal, a product of oxidative stress, leads to an antioxidant response in optic nerve head astrocytes. Exp Eye Res 84:444-454

53. Hernandez MR, Miao H, Lukas T (2008) Astrocytes in glaucomatous optic neuropathy. Prog Brain Res 173:353-373
54. Lee I, Lee H, Kim JM, Chae EH, Kim SJ, Chang N (2007) Shortterm hyperhomocysteinemia-induced oxidative stress activates retinal glial cells and increases vascular endothelial growth factor expression in rat retina. Biosci Biotechnol Biochem 71:1203-1210

55. Luo C, Yang X, Kain AD, Powell DW, Kuehn MH, Tezel G (2010) Glaucomatous tissue stress and the regulation of immune response through glial Toll-like receptor signaling. Invest Ophthalmol Vis Sci 51:5697-5707

56. McElnea EM, Quill B, Docherty NG, Irnaten M, Siah WF, Clark $\mathrm{AF}$ et al (2011) Oxidative stress, mitochondrial dysfunction and calcium overload in human lamina cribrosa cells from glaucoma donors. Mol Vis 17:1182-1191

57. Ramirez AI, Salazar JJ, de Hoz R, Rojas B, Gallego BI, SallinasNavarro M et al (2010) Quantification of the effect of different levels of IOP in the astroglia of the rat retina ipsilateral and contralateral to experimental glaucoma. Invest Ophthalmol Vis Sci 51:5690-5696

58. Gallego BI, Salazar JJ, de Hoz R, Rojas B, Ramirez AI, SalinasNavarro M et al (2012) IOP induces upregulation of GFAP and MHC-II and microglia reactivity in mice retina contralateral to experimental glaucoma. J Neuroinflammation 9:92

59. Wei MC, Zong WX, Cheng EH, Lindsten T, Panoutsakopoulou V, Ross AJ et al (2001) Proapoptotic BAX and BAK: a requisite gateway to mitochondrial dysfunction and death. Science 292:727-730

60. Wasiak S, Zunino R, McBride HM (2007) Bax/Bak promote sumoylation of DRP1 and its stable association with mitochondria during apoptotic cell death. J Cell Biol 177:439-450

61. Antonsson B, Conti F, Ciavatta A, Montessuit S, Lewis S, Martinou I et al (1997) Inhibition of Bax channel-forming activity by Bcl-2. Science 277:370-372

62. Schlesinger PH, Gross A, Yin XM, Yamamoto K, Saito M, Waksman $G$ et al (1997) Comparison of the ion channel characteristics of proapoptotic BAX and antiapoptotic BCL-2. Proc Natl Acad Sci USA 94:11357-11362

63. Desagher S, Martinou JC (2000) Mitochondria as the central control point of apoptosis. Trends Cell Biol 10:369-377

64. Oltvai ZN, Milliman CL, Korsmeyer SJ (1993) Bcl-2 heterodimerizes in vivo with a conserved homolog, Bax, that accelerates programmed cell death. Cell 74:609-619

65. Yang E, Zha J, Jockel J, Boise LH, Thompson CB, Korsmeyer SJ (1995) Bad, a heterodimeric partner for Bcl-XL and Bcl-2, displaces Bax and promotes cell death. Cell 80:285-291

66. Tsujimoto Y, Shimizu S (2007) Role of the mitochondrial membrane permeability transition in cell death. Apoptosis $12: 835-840$

67. Linkermann A, Brasen JH, Darding M, Jin MK, Sanz AB, Heller JO et al (2013) Two independent pathways of regulated necrosis mediate ischemia-reperfusion injury. Proc Natl Acad Sci USA 110:12024-12029

68. Chan SW, Nguyen PN, Ayele D, Chevalier S, Aprikian A, Chen JZ (2011) Mitochondrial DNA damage is sensitive to exogenous $\mathrm{H}(2) \mathrm{O}(2)$ but independent of cellular ROS production in prostate cancer cells. Mutat Res 716:40-50

69. Beal MF (1995) Aging, energy, and oxidative stress in neurodegenerative diseases. Ann Neurol 38:357-366

70. Ekstrand MI, Falkenberg M, Rantanen A, Park CB, Gaspari M, Hultenby K et al (2004) Mitochondrial transcription factor A regulates mtDNA copy number in mammals. Hum Mol Genet 13:935-944 